\title{
Childhood adversity and adult personality
}

\author{
Stephen Rosenman, Bryan Rodgers
}

\begin{abstract}
Objectives: To explore how recalled childhood adversity affects trait measures of personality in three age cohorts of an Australian adult population and to examine the effects of particular adversities on adult personality traits.

Method: A total of 7485 randomly selected subjects in the age bands of 20-24, 40-44 and 60-64 years were interviewed at the outset of a longitudinal community study of psychological health in the Canberra region of Australia. In the initial interview, subjects answered 17 questions about domestic adversity and three questions on positive aspects of upbringing to age 16 years. Personality traits were measured by Eysenck Personality Questionnaire, Behavioural Activation and Inhibition Scales, Positive and Negative Affect Scales and a measure of dissocial behaviours.

Results: Higher levels of childhood adversity substantially increase the risk of high neuroticism $(O R=2.6)$ and negative affect $(O R=2.6)$, less for behavioural inhibition $(O R=1.7)$ and for dissocial behaviour $(O R=1.7)$. No significant effect is seen for extraversion, psychoticism or behavioural activation. Age and gender had little effect on the pattern of risk. Maternal depression has significant and substantial independent effects on measures of neuroticism and negative affect as well as most other measures of personality.

Conclusion: Childhood domestic adversity has substantial associations with clinically important aspects of personality: neuroticism and negative affect. Only small effects are seen on behavioural inhibition and dissocial behaviour, and no significant effect on extraversion and behavioural activation. These unexpected findings contradict clinical belief. Maternal psychological ill-health is pre-eminent among adversities predicting later disadvantageous traits, even for those traits that had only the slightest association with childhood adversity. Consequences of childhood adversity prevail throughout the lifespan in men and women equally. The study underlines the importance of childhood domestic adversity and especially maternal psychological ill-health as a target for preventive intervention for psychological difficulties at all ages.
\end{abstract}

Key words: childhood adversity, community survey, maternal depression, neuroticism, personality.

\section{Australian and New Zealand Journal of Psychiatry 2006; 40:482-490}

Tis education forms the common mind, Just as the twig is bent, the tree's inclined.

Attrib. Alexander Pope

Stephen Rosenman, Visiting Fellow (Correspondence); Bryan Rodgers, Senior Fellow

Centre for Mental Health Research, Australian National University, Canberra, Australian Capital Territory 0200, Australia. Email: sjr@netspeed.com.au

Received 29 March 2005; revised 27 April 2005; accepted 4 May 2005.
Childhood experience is central to the development of personality [1]. This is an historical dogma, a foundation of clinical personality theory and a basis of anamnestic approaches to practice. There is a large literature already about the relationships between environment, especially early adversity, and personality [2,3]. The weight of literature over generations shows the effects of severe maltreatment $[4,5]$ and the psychiatric literature is dominated by associations of childhood adversity with diagnosed illnesses or clinically defined groups [6]. The subclinical 
effect of ordinary adversities on ordinary personalities has been the province of the psychological literature even though ordinary adversity is the stuff of daily clinical practice and is more approachable and modifiable than extreme adversity.

Psychiatry represents personality as a well-established object, fixed by endowment and experience. In fact, personality is an ineffable concept, clear only until we attempt to define it when the concept becomes vague and unbounded. Medicine has resolved this vagueness by taking a disorder-specific approach to personality, lumping the variegated elements of behaviour into disorderly categories of disorder. Psychologists' taxonomies and measures of personality have been richer and more perspicacious representations even though disputes continue about the discrimination of enduring dispositions from present states [7] and about the persistence of personality $[8,9]$. Neuroticism, extraversion-introversion, psychoticism [10], behavioural inhibition and activation [11,12], and positive or negative affectivity [13] are closely related psychological conceptions which tie together key elements of personality [14].

Clinically, neuroticism and negative affectivity predict depression, anxiety, post-traumatic stress disorders and substance use [15-19] and neuroticism predominates in those people who come to report subjective psychological distress [20]. Psychoticism (in Eysenck's description) and extraversion associate with antisocial personality [21]. Aspects of behavioural activation, especially reward response, are seen in eating disorders and alcohol abuse [22] while defects of inhibition appear understandably with attention deficits and hyperactivity disorders [23]. Explicitly these traits are embedded in the structure of the brain and, implicitly, precede experience. However, as lasting behavioural alterations follow experience [24] and as endowment and environment interact throughout life, the causal relationships between personality, endowment and experience cannot be fixed or resolved once and for all. However, that relationship may be illuminated and illuminating it may inform environmental interventions for individuals and populations [25].

While the existing literature is large, the subject remains important because of its consequences across populations. Communities vary in their own particular adversities and modulate the impact of adversities in their own ways. The effects of adversity will be more easily seen in personality traits that are normally distributed throughout the population than in diagnoses which are eccentrically distributed in subgroups.

The aim of this study is to test the relationship between retrospectively reported domestic adversity in childhood (to age 16) with trait measures of personality in three age cohorts of an Australian adult population. The study also examines the effects of particular adversities on adult personality traits.

\section{Method}

\section{Subjects}

In the years 1999-2002, the PATH project conducted its initial interviews at the commencement of a long-term longitudinal study. The data in this paper come from that initial comprehensive interview with 7485 subjects, 3674 men and 3809 women in three age groups: 20-24 years (2404 subjects), 40-44 years (2530 subjects) and 60-64 years (2551 subjects).

Subjects were randomly selected from the electoral rolls covering Canberra (Australian Capital Territory) and Queanbeyan (New South Wales). Of the 12409 people approached to take part in the study, 4917 (36.9\%) either refused or had insufficient command of English to take part. Subjects identified themselves as Caucasian (94.1\%), Asian $(3.1 \%)$ or 'other' $(2.7 \%)$.

As refusal and exclusion were not random, the interviewed sample of 7485 subjects was slightly biased. The sample was better educated (66\% of the sample had post-school qualifications vs $53 \%$ of the host population - Fisher's exact $\mathrm{p}<0.001$ although there was no difference in the level of university education), more likely to be employed (79\% vs $75 \%$ - Fisher's exact $\mathrm{p}<0.001)$ and more likely married $(46 \%$ vs $43 \%$ - Fisher's exact $\mathrm{p}<0.002$ ).

\section{Measures}

Subjects were comprehensively examined about history, social circumstance, personality and cognitive function, recent psychological symptoms, drug and alcohol use. All questions were self-completed on a hand-held computer in an interview supervised by a trained lay interviewer who did not see answers but was available for help. The interview asked respondents about their childhood up to the age of 16 years. Six items covered lack of affection, nervous or emotional trouble and drinking or other drug use in father and mother figures, and two items covered conflict in the household and parental divorce or separation. Eight items covered neglect, authoritarian upbringing, parental psychological abuse, witnessed physical or sexual abuse, parental physical abuse, physical punishment and sexual abuse by a parent. One item covered childhood poverty or financial hardship. There was one additional 'catch-all' narrative item allowing the description of other types of mistreatment. The 'catch-all' item was little used, indicating the comprehensiveness of the particular closed questions. 'Catch-all' answers were coded into the appropriate closed item or were excluded where they related to adversities outside the family focus of the study. Three further items asked about positive aspects of upbringing; happiness, normality and 'parents did their best'.

Several items were adopted and adapted from the Parental Bonding Instrument [26], the British National Survey of Health and Development [27] and the US National Comorbidity Survey [28]. Nine additional items were derived from open-ended responses in a previous cross-sectional study in the Canberra region that utilized items with 
more open-ended responding [29]. A scale score of 'adversity' (Cronbach $\alpha=0.756$ ) was created as an unweighted sum of the 17 adversity items (excluding positive aspects of upbringing). The adversities and their prevalence in this population have been reported previously [30].

Of several measures of personality in the study, two principal measures are reported. The 36 items of the Eysenck Personality Questionnaire (EPQ) - Revised [31] include Extraversion, Neuroticism and Psychoticism scales but not the Lie scale. The 24 items of the Behavioural Inhibition and Activation scales (BIS/BAS) were scored to yield four behavioural scales: inhibition, drive, fun seeking and reward response [12].

Twenty items of the Positive and Negative Affect Scales [13] were included in the study. However, they relate to present (preceding month) symptoms only and cannot be taken to represent enduring aspects of personality. They are included as indicators of current emotional reactivity.

Alcohol use was screened by the Alcohol Use Disorders Identification Test [32] and other substance use, including tobacco, by established measures [33-35].

Perceived social support was measured by the Social Support Scale [36] which yields six components of positive and negative social support from family, friends and partner. The measures of friends' and partners' positive and negative support were combined into scores of positive and negative social support by summing standardized (z) scores on each component. Family support was excluded as it is confounded with the adversity measure. Perceived social support (positive and negative) can be seen as an indicator rather than a contributor to personality [37]. Therefore, it is treated in this study as a dependent indicator of personality.

A measure of dissocial behaviour was created by a principal components factor analysis of a number of items with face validity for social behaviour, relationships and affective control. The factor called dissocial behaviour loaded heavily on substance use and problems (alcohol, marijuana, tobacco), police and employment problems, with small loadings on social support, anxiety and financial problems.

Data were analysed with SPSS version 11.0 (SPSS Inc., Chicago, IL, USA). Individual adversity measures were reduced to dichotomous scores for analysis. Correlations reported for the whole population in Table 1 are partial correlations that correct for age and gender. For odds ratios reported in Tables 2 and 3, adversity was dichotomized at five or more adversities representing the top decile of adversity and was considered 'high adversity'. The personality measures in Table 2 are dichotomized at the top quartile on each measure. Regressions were corrected for age and gender by entering age and gender first and then entering stepwise the independent predictors.

\section{Results}

\section{Intercorrelations of measures}

Correlations between the personality measures are shown in Table 1. Correlations are corrected for age and gender.

Eysenck Personality Questionnaire's Neuroticism is well correlated with BIS and higher Negative Affect (and lower Positive Affect). Eysenck Personality Questionnaire's Extraversion correlates with BAS drive and fun-seeking, and with Positive Affect.

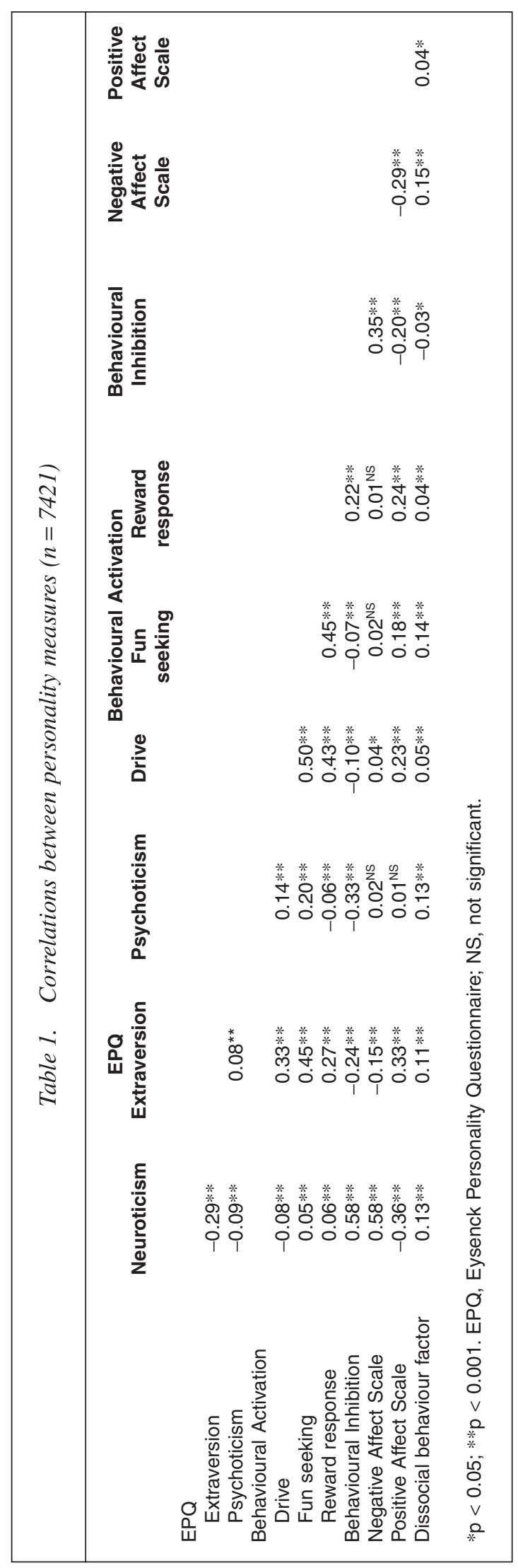


Table 2. Risk (odds ratios) for highest quartiles on personality measures for subjects with five or more childhood adversities

\begin{tabular}{|c|c|c|c|c|c|c|}
\hline & $\begin{array}{l}\text { Total sample } \\
(n=7418)\end{array}$ & $\begin{array}{c}20-24 \text { years } \\
(n=2375)\end{array}$ & $\begin{array}{c}\text { 40-44 years } \\
(n=2508)\end{array}$ & $\begin{array}{c}\text { 60-64 years } \\
(n=2535)\end{array}$ & $\begin{array}{l}\text { Female } \\
(n=3782)\end{array}$ & $\begin{array}{c}\text { Male } \\
(n=3648)\end{array}$ \\
\hline \multicolumn{7}{|l|}{ EPQ (highest quartile) } \\
\hline Neuroticism & $2.6 *$ & $3.4 *$ & $2.2 *$ & $2.7^{*}$ & $2.4 *$ & $2.6 *$ \\
\hline Extraversion & $1.0^{\mathrm{NS}}$ & $1.0^{\mathrm{NS}}$ & $1.2^{\mathrm{NS}}$ & $0.9^{\text {NS }}$ & $1.0^{\mathrm{NS}}$ & $1.0^{\mathrm{NS}}$ \\
\hline Psychoticism & $1.4^{\mathrm{NS}}$ & $1.0^{\mathrm{NS}}$ & $1.7^{*}$ & $1.2^{*}$ & $1.4^{*}$ & $1.5^{*}$ \\
\hline \multicolumn{7}{|c|}{ Behavioural Activation (highest quartile) } \\
\hline Drive & $1.1^{\mathrm{NS}}$ & $1.0^{\mathrm{NS}}$ & $1.2^{\mathrm{NS}}$ & $1.0^{\mathrm{NS}}$ & $1.1^{\mathrm{NS}}$ & $1.2^{\mathrm{NS}}$ \\
\hline Fun seeking & $1.4^{\mathrm{NS}}$ & $1.2^{\mathrm{NS}}$ & $1.4 *$ & $1.0^{\mathrm{NS}}$ & $1.1^{\mathrm{NS}}$ & $1.3^{\mathrm{NS}}$ \\
\hline Reward response & $1.2^{\mathrm{NS}}$ & $1.2^{\mathrm{NS}}$ & $1.2^{\mathrm{NS}}$ & $1.3^{\mathrm{NS}}$ & $1.1^{\mathrm{NS}}$ & $1.1^{\mathrm{NS}}$ \\
\hline $\begin{array}{l}\text { Behavioural Inhibition } \\
\text { (highest quartile) }\end{array}$ & $1.7^{*}$ & $1.8^{*}$ & $1.5^{*}$ & $2.1 *$ & $1.5^{*}$ & $2.0 *$ \\
\hline $\begin{array}{l}\text { Positive Affect Scale } \\
\text { (lowest quartile) }\end{array}$ & $1.5^{*}$ & $1.9 *$ & $1.4^{*}$ & $1.3^{\mathrm{NS}}$ & $1.4^{*}$ & $1.5^{*}$ \\
\hline $\begin{array}{l}\text { Negative Affect Scale } \\
\text { (highest quartile) }\end{array}$ & $2.6 *$ & $3.1^{*}$ & $2.5^{*}$ & $2.5^{*}$ & $2.3^{*}$ & $2.7^{*}$ \\
\hline $\begin{array}{l}\text { Dissocial behaviour } \\
\text { (highest quartile) }\end{array}$ & $1.7^{*}$ & $2.3^{*}$ & $1.4^{*}$ & $1.7^{*}$ & $1.7^{*}$ & $1.7^{*}$ \\
\hline
\end{tabular}

\begin{tabular}{|lc|}
\hline \multicolumn{2}{|c|}{ Table 3. Risk (odds ratios) for dissocial behaviours } \\
and social difficulty in subjects with five or more \\
childhood adversities \\
\hline \multicolumn{2}{|c|}{ Behaviour or relationship } \\
Police or court appearance & Odds ratio \\
Sacked from job & $2.2^{*}$ \\
Serious financial problems & $2.2^{*}$ \\
Marijuana use & $3.0^{*}$ \\
High alcohol use & $1.5^{*}$ \\
Alcohol problems & $1.5^{*}$ \\
Smokes cigarettes & $1.6^{*}$ \\
Marital separation or divorce & $1.5^{*}$ \\
Positive social support (lowest quartile) & $1.9^{*}$ \\
Negative social support (highest quartile) & $2.0^{*}$ \\
& $2.1^{*}$ \\
*p $<0.05$. & \\
\end{tabular}

Eysenck Personality Questionnaire's Psychoticism correlates positively with some elements of BAS and negatively with BIS. The correlates of BIS indicate that it lies between EPQ Neuroticism and Introversion (the negative pole of Extraversion). The elements of BAS, such as drive, fun-seeking and reward response, correlate differently with other measures of personality suggesting activation is not a unitary psychological mechanism.

Dissocial behaviour shows small although significant correlations with other measures. Its correlations with aspects of BAS are no greater than associations with current Negative Affect or with Neuroticism and Extraversion.

\section{Childhood adversity and personality measures}

Table 2 shows the odds ratios for scoring in the top quartile of the personality measure for subjects experiencing five or more adversities in childhood.

High childhood adversity substantially increases the risk of higher levels of Neuroticism and Negative Affect. Smaller risks are seen for BIS, lower Positive Affect and dissocial behaviour. Risk was not significant for Extraversion, Psychoticism or any element of BAS.

The same pattern of risk is seen in each age group. Although risks tend to diminish with age, none of the risks is significantly lower in the oldest age cohort. There is no significant difference between men and women.

\section{Childhood adversity and social behaviours and relationships}

The measure of dissocial behaviour is a derived factor with principal loadings on problems with police, employment, financial problems and substance use and abuse. Relationship measures include divorce or marital separation and perceived positive and negative social support.

Table 3 shows the odds ratios for components of dissocial behaviour and social difficulty for subjects with the highest childhood adversity.

Childhood adversity creates significant risk for various dissocial behaviours including police problems and substance abuse. The risk of perceived negative (critical or absent) social support and poorer positive social support is significant and substantial. There is no significant difference between men and women. 


\section{The impact of individual adversities}

After controlling for age and gender, a stepwise regression was done in which the individual adversities were independent predictors for each of the principal measures of personality for which adversity created substantial risk. In this analysis, the three items of positive aspects of upbringing were included as they are likely to mitigate the impact of adversity. Significant regression coefficients are shown in Table 4.

Maternal psychological ill-health contributes to all the measures of personality, current negative affect and social support. Paternal psychological ill-health contributes substantially less. Happiness of childhood is an independent mitigation of negative measures. Of other adversities, mental cruelties outweigh physical abuses in their independent impact. Domestic conflict is prominent in effect, but for measures of Negative Affect, actual separation or divorce appears to mitigate the effect of conflict.

Paternal psychological ill-health makes a significant independent contribution to personality. This independent effect is seen despite significant co-occurrence between maternal and paternal psychological symptoms. Husbands of depressed mothers were three times more likely to be depressed or substance-abusing than husbands of nondepressed mothers $(\mathrm{OR}=3.18,95 \% \mathrm{CI}=2.84-3.56)$. The corollary of this is that the father's good psychological health mitigates the effect of maternal depression on the child.

Dissocial behaviour is least affected by childhood adversity although maternal difficulties including psychological problems and substance abuse by both parents are significant predictors of the small amount of explained variance. Poverty is a small mitigation.

Perceived negative social support relates to disturbed parental and household relationships, especially conflict and authoritarian control.
Perceived positive social support reflects parental affection and the absence of authoritarian or abusive relationships while relative material privileges was a small but significant contributor.

Separate analyses, not reported here, were also performed by gender and showed few differences in the predictors for men and women. Women showed greater sensitivities to household conflict which predicted neuroticism, to maternal affection which predicted later social support and to maternal substance use which predicted dissocial behaviour. Men showed greater sensitivities to paternal affection which predicted later social support and paternal substance use which predicted dissocial behaviour.

\section{Discussion}

The effect of childhood adversity on adult personality is visible in this large sample of three adult-age cohorts. The risks of neuroticism, behavioural inhibition and current negative affect are significantly and substantially affected by higher levels of domestic adversity and by particular adversities in childhood. The measures most affected are those that reflect susceptibility to anxiety, avoidance and inhibition. Childhood adversity has much less effect on current positive affect and no significant effect on extraversion or behavioural activation, which are measures that reflect drive, sociability and engagement with the world.

Surprisingly, there was little difference between the reactions of men and women and the consequences

Table 4. Stepwise regression coefficients for principal personality measures (controlling age and gender)

\begin{tabular}{|c|c|c|c|c|c|c|}
\hline \multirow[t]{2}{*}{ Adversity } & \multicolumn{6}{|c|}{ Standardized coefficient (Beta) } \\
\hline & $\begin{array}{c}E P Q \\
\text { neuroticism }\end{array}$ & $\begin{array}{l}\text { Behavioural } \\
\text { Inhibition }\end{array}$ & $\begin{array}{c}\text { Negative } \\
\text { Affect Scale }\end{array}$ & $\begin{array}{c}\text { Negative } \\
\text { Social Support }\end{array}$ & $\begin{array}{c}\text { Positive } \\
\text { Social Support }\end{array}$ & $\begin{array}{l}\text { Dissocial } \\
\text { behaviour }\end{array}$ \\
\hline Mother nervous or depressed & $0.12^{* *}$ & $0.06 * *$ & $0.12 * *$ & $0.09 * *$ & $-0.04 * *$ & $0.05^{* *}$ \\
\hline Happy childhood & $-0.14 * *$ & $-0.06 *$ & $-0.10 * *$ & $-0.09 * *$ & $0.11 * *$ & \\
\hline Father nervous or depressed & $0.06 * *$ & $0.06 * *$ & $0.07 * *$ & $0.06 * *$ & & \\
\hline Humiliation and mental cruelty & $0.03 * *$ & $0.03 *$ & $0.04 * *$ & & & \\
\hline Household conflict & $0.04 * *$ & & $0.05^{* *}$ & & & \\
\hline Parents separated/divorced & & $-0.03 *$ & $-0.04 * *$ & & & \\
\hline Witnessed physical or sex abuse & $-0.03 *$ & $-0.02 *$ & & & & \\
\hline Strict authoritarian upbringing & & & $0.03 * *$ & & & \\
\hline Excessive physical punishment & & & & $0.06 * *$ & & \\
\hline Verbal abuse & & & & & & $0.03^{* *}$ \\
\hline Poverty & $0.03^{* *}$ & & $0.03 *$ & & & $-0.03 * *$ \\
\hline Neglect & & & $0.05 * *$ & & & \\
\hline Father unaffectionate & & & & & $-0.07 * *$ & \\
\hline Mother unaffectionate & & & & & $-0.05^{* *}$ & \\
\hline Mother drank or used drugs & & & & & & $0.05 * *$ \\
\hline Father drank or used drugs & & & & & & $0.07 * *$ \\
\hline $\begin{array}{l}\text { Proportion variance explained } \\
\text { by adversities after fitting age } \\
\text { and gender }(\%)\end{array}$ & 7.4 & 1.8 & 7.6 & 3.4 & 3.6 & 1.5 \\
\hline
\end{tabular}


of adversity diminish little across the age groups examined.

Maternal psychological ill-health stands out for the size and consistency of its contribution across personality measures, at least across those measures associated with negative affect and personal discomfort. Paternal psychological ill-health has an independent but smaller impact and good psychological health in fathers may mitigate the impact of ill-health in mothers. This echoes repeated findings that underline the very particular role of maternal psychological ill-health in the future difficulties of the child [38].

A 'happy' childhood appears to mitigate the consequence of adversity. This suggests that other sources of support or temperamental optimism can counteract adversity's effect. Poverty is a significant but surprisingly small contributor to neuroticism although its effect may be buried in associated adversities such as parental difficulties and marital separation.

Perceived social support in the adults' current social world is taken here as an indicator of personality function [37]. Childhood adversity has different effects on positive and negative social support. Perception of negative social support flows from domestic conflict and harsh parental relationships. Parental separation or divorce mitigates the baleful effect of conflict, suggesting that parental separation is less damaging than continuing marital conflict. Perception of positive current social support appears to reflect the warmth of the home atmosphere and it is the only dependent characteristic in which reported parental affection has significant effect. Childhood adversity appears to continue its effect into adulthood in part through its influence on the capacity to make and maintain satisfying personal and social relationships.

Childhood adversity made small but significant contributions to Psychoticism (which these days is seen as a measure of 'psychopathy' [39]) and to dissocial behaviour. The paucity of the contribution of childhood adversity to dissocial behaviour was unexpected.

\section{Limitations}

Measures of personality based on limited and constrained self-reports cannot adequately portray a rich and variegated idea of personality or a wide enough range of traits to cover the potential consequences of the complexities of upbringing. Yet evidence suggests that traits such as neuroticism are subtle, pervasive and influential and consistently emerge in many analyses of personality [40]. The traits are reasonably represented by the scales [41].

Scales that purport to measure enduring personality traits may be contaminated with transient states. This is an irreducible problem of cross-sectional studies and may be elucidated by the later longitudinal examination of data. The usual caveats must be applied to the assumption of cause between the described adversity and the resultant personality. Personality may influence the reporting as well as the experience of adversity and retrospective recall of adversity in childhood may be unreliable or influenced by present events. Recall bias is hard to avoid in retrospective studies [42] and symptomatically depressed subjects are more likely to recall mood congruent memories [43]. Answers to factual questions (such as separations, actual violence, etc.) can be reasonably assumed accurate [44] and, although physical and sexual abuse appears to be under-reported [45,46], family studies tend to corroborate abuse reports [47]. While retrospective reports are inevitably imperfect, a broad literature indicates that they are not systematically distorted in such a way as to inflate associations with mental health problems $[43,44]$.

Questions about adversities included only domestic and immediate family experience. No data are available for those adversities, especially assaults, injuries, disasters and distress that occur outside the family. The interview procedure allowed clarification of questions, but did not allow probes or subtle discriminations of adversity reports. Misunderstanding was possible either because of difficulties of comprehension or because of unfamiliarity with the computer medium. However, a 'catch-all' narrative question about adversity at the end yielded responses in only $3.9 \%$ of cases of which three quarters were appropriately coded into the items in the scale.

Dissocial behaviour is examined as an indicator of antisocial personality traits. The factor is composed primarily of substance use and problems (alcohol, marijuana, tobacco), police and employment problems, with small loadings on social support, anxiety and financial problems. The indicator is unvalidated.

\section{Implications}

Childhood adversity has a special impact on those personality measures that reflect lasting susceptibility to anxiety and negative affect. In this, the consequence of childhood adversity resembles the consequence of other trauma and possibly exerts its effect through the same mechanisms by which trauma leaves a lasting sensitization of mechanisms of anxiety and negative affect $[48,49]$.

The consequences of childhood adversity for personality diminish only slightly with age and subsequent experience little dilutes its effects. Childhood experience 
remains primary, intrudes into subsequent experience and exerts its effect throughout life.

Extraversion and behavioural activation appear to be more independent from childhood adversity, a finding that disagrees with other studies [6,50]. This relative independence does not necessarily mean that extraversion and behavioural activation are 'innate'. Few items in the questionnaire reflected environments that may foster confidence and self-expression and the retrospective report of the family environment may be glossed by the extravert. However, it does suggest that the determinants of extraversion and activation will be harder to discern and modify.

Clinically, childhood adversity affects personality traits that relate directly to clinical conditions [15-19,2123], but also has an indirect effect on morbidity by increasing sensitivities to later adverse experience [20]. The present findings should widen the scope of prevention to the adversities experienced in childhood. The predominance of the effect of maternal depressive symptoms underlines the importance of clinical services to mothers among the services for the welfare of the child.

The relatively small contribution of childhood adversity to dissocial behaviour is surprising and contradicts clinical beliefs and other studies [51-55]. More subtle studies on 'externalizing' difficult behaviours have shown complex moderators of family environment effects that blur the visibility of the consequences [56]. Moreover, the little evidence that is available suggests that the broader social environment outside the family plays a larger role in antisocial personality traits than in neurotic personality traits [6]. The paucity of relationship must temper expectations that family interventions will diminish the risk of later dissocial behaviour.

Uncertainties in the meaning of 'personality' are not answered here. Eysenck himself linked the EPQ Neuroticism and Introversion-Extraversion traits with enduring and separate susceptibilities to negative affect and positive affect, respectively [14]. Gray reformulated Eysenck's traits in terms of behaviour rather than experienced affect [11] and this reformulation underlies the BIS and BAS used in this study [12]. Data in this study support the relationship between neuroticism and negative affect and conceptions of BIS and BAS as rotations of Eysenck's trait axes.

\section{Conclusion}

Childhood domestic adversity has significant and substantial associations with clinically important aspects of personality. The relationship of childhood adversity with neuroticism, behavioural inhibition and negative affect conforms to other research and long-held clinical belief. The small effect on dissocial behaviour and the relative independence of extraversion, behavioural activation and dissocial behaviour is unexpected and contradicts clinical belief.

Maternal psychological ill-health was pre-eminent among adversities predicting later disadvantageous traits, even for those traits that had the smallest association with childhood adversity. Fathers played much smaller roles.

The study underlines the importance of childhood domestic adversity and especially maternal psychological ill-health as a target for preventive intervention for later psychological difficulties at all ages.

\section{Acknowledgements}

Thanks to Trish Jacomb, Karen Maxwell and the team of the Centre for Mental Health Research interviewers for their assistance with this study. Andrew Mackinnon provided statistical advice. Funding was provided by Program Grant No. 179805 from the National Health and Medical Research Council and a grant from the Australian Rotary Health Research Fund.

\section{References}

1. Bowlby J. Attachment and loss. London: Hogarth, 1969.

2. Rutter M. The interplay of nature, nurture, and developmental influences: the challenge ahead for mental health. Archives of General Psychiatry 2002; 59:996-1000.

3. Nakao K, Takaishi J, Tatsuta $\mathrm{K}$ et al. The influences of family environment on personality traits. Psychiatry and Clinical Neuroscience 2000; 54:91-95.

4. Spitz R, Wolf K. Anaclitic depression: an inquiry into the genesis of psychiatric conditions in early childhood II. The Psychoanalytic Study of the Child 1946; II:313-342.

5. Ethier LS, Lemelin JP, Lacharite C. A longitudinal study of the effects of chronic maltreatment on children's behavioral and emotional problems. Child Abuse and Neglect 2004; 28:12651278.

6. Kessler RC, Davis CG, Kendler KS. Childhood adversity and adult psychiatric disorder in the US National Comorbidity Survey. Psychological Medicine 1997; 27:1101-1119.

7. Ormel J, Rosmalen J, Farmer A. Neuroticism: a non-informative marker of vulnerability to psychopathology. Social Psychiatry and Psychiatric Epidemiology 2004; 39:906-912.

8. Mischel W. Continuity and change in personality. American Psychologist 1969; 24:1012-1018.

9. Seivewright $\mathrm{H}$, Tyrer $\mathrm{P}$, Johnson T. Change in personality status in neurotic disorders. Lancet 2002; 359:2253-2254.

10. Eysenck HJ, Eysenck SBG. Manual of the Eysenck Personality Inventory. Kent: Hodder and Stoughton, 1964.

11. Gray JA. Three fundamental emotion systems. In: Ekman P, Davidson RJ, eds. The nature of emotion: fundamental questions. New York: Oxford University Press, 1994; 243-247.

12. Carver CS, White TL. Behavioural inhibition, behavioural activation and affective responses to impending reward and punishment: the BIS/BAS Scales. Journal of Personality Social Psychology 1994; 67:319-333. 
13. Watson D, Clark LA, Tellegen A. Development and validation of brief measures of positive and negative affect: the PANAS scales. Journal of Personality Social Psychology 1988; 54:10631070.

14. Zelenski JM, Larsen RJ. Susceptibility to affect: a comparison of three personality taxonomies. Journal of Personality 1999; 67:761-791.

15. Bienvenu OJ, Stein MB. Personality and anxiety disorders: a review. Journal of Personality Disorders 2003; 17:139_ 151.

16. Jackson KM, Sher KJ. Alcohol use disorders and psychological distress: a prospective state-trait analysis. Journal of Abnormal Psychology 2003; 112:599-613.

17. Roberts SB, Kendler KS. Neuroticism and self-esteem as indices of the vulnerability to major depression in women. Psychological Medicine 1999; 29:1101-1109.

18. Mulder RT. Personality pathology and treatment outcome in major depression: a review. American Journal of Psychiatry 2002; 159:359-371.

19. Cox BJ, MacPherson PS, Enns MW, McWilliams LA. Neuroticism and self-criticism associated with posttraumatic stress disorder in a nationally representative sample. Behavior Research and Therapy 2004; 42:105-114.

20. Neeleman J, Bijl R, Ormel J. Neuroticism, a central link between somatic and psychiatric morbidity: path analysis of prospective data. Psychological Medicine 2004; 34:521-531.

21. Deary IJ, Peter A, Austin E, Gibson G. Personality traits and personality disorders. British Journal of Psychology 1998; 89:647-661.

22. Loxton NJ, Dawe S. Alcohol abuse and dysfunctional eating in adolescent girls: the influence of individual differences in sensitivity to reward and punishment. International Journal of Eating Disorders 2001; 29:455-462.

23. Quay HC. Inhibition and attention deficit hyperactivity disorder. Journal of Abnormal Child Psychology 1997; 25: 7-13.

24. Sapolsky RM. Stress, glucocorticoids, and damage to the nervous system: the current state of confusion. Stress 1996; $1: 1-19$.

25. Hirshfeld-Becker DR, Biederman J, Faraone SV, Segool N, Buchwald J, Rosenbaum JF. Lack of association between behavioral inhibition and psychosocial adversity factors in children at risk for anxiety disorders. American Journal of Psychiatry 2004; 161:547-555.

26. Parker G. Parental characteristics in relation to depressive disorders. British Journal of Psychiatry 1979; 134:138-147.

27. Rodgers B. Reported parental behaviour and adult affective symptoms. 1. Associations and moderating factors. Psychological Medicine 1996; 26:51-61.

28. Kessler RC, Magee WJ. Childhood adversities and adult depression: basic patterns of association in a US national survey. Psychological Medicine 1993; 23:679-690.

29. Henderson AS, Jorm AF, Korten AE, Jacomb P, Christensen H, Rodgers B. Symptoms of depression and anxiety during adult life: evidence for a decline in prevalence with age. Psychological Medicine 1998; 28:1321-1328.

30. Rosenman S, Rodgers B. Childhood adversity in an Australian population. Social Psychiatry and Psychiatric Epidemiology 2004; 39:695-702.

31. Eysenck SBG, Eysenck HJ, Barrett P. A revised version of the Psychoticism scale. Personality and Individual Differences 1985; 6:21-29.

32. Saunders JB, Aasland OG, Babor TF, de la Fuente JR, Grant M. Development of the alcohol use disorders identification test (AUDIT): WHO collaborative project on early detection of persons with harmful alcohol consumption - II. Addiction 1993; 88:791-804.

33. Social Science Data Archives, Australian National University. National campaign against drug abuse social issues survey: user's guide. Canberra: SSDA (No. 765), 1993.
34. Brown RL, Leonard T, Saunders LA, Papasoullotis O. A twoitem screening test for alcohol and other drug problems. Journal of Family Practice 1997; 44:151-160.

35. Australian Institute of Health and Welfare. 2001 National drug strategy household survey. Drug Statistics Series No 9. Canberra: AIHW, 2001.

36. Schuster TL, Kessler RC, Aseltine RH. Supportive interactions, negative interactions and depressed mood. American Journal of Community Psychology 1990; 18:423-437.

37. Henderson S. Social relationships, adversity and neurosis: an analysis of prospective observations. British Journal of Psychiatry 1981; 138:391-398.

38. Burke L. The impact of maternal depression on familial relationships. International Review of Psychiatry 2003; 15:243255.

39. Witherspoon AD, Long CK, Farmer R, Hitson D, Thompson S. Correlation for Eysenck's measure of Psychoticism and the Environmental Deprivation Scale. Psychological Reports 1997; 81:1416-1418.

40. Widiger TA. A dimensional model of personality disorder. Current Opinion in Psychiatry 2005; 18:41-43.

41. Farley FH, Soper RE. Global self-rating validation of the measurement of extraversion and neuroticism. Educational and Psychological Measurement 1976; 36:487-490,.

42. Neugebauer R, Ng S. Differential recall as a source of bias in epidemiological research. Journal of Clinical Epidemiology 1990; 43:1337-1341.

43. Brewin CR, Andrews B, Gotlib IH. Psychopathology and early experience: a reappraisal of retrospective reports. Psychological Bulletin 1993; 113:82-98.

44. Jorm AF, Henderson AS. Memory bias in depression: implications for risk factor studies relying on self-reports of exposure. International Journal of Methods in Psychiatric Research 1992; 2:31-38.

45. Widom CS, Shepard RL. Accuracy of adult recollections of childhood victimization: Part 1 . Childhood physical abuse. Psychological Assessment 1996; 8:412-421.

46. Widom CS, Morris S. Accuracy of adult recollections of childhood victimization: Part 2. Childhood sexual abuse. Psychological Assessment 1997; 9:34-46.

47. Bifulco A, Brown GW, Lillie A, Jarvis J. Memories of childhood neglect and abuse: corroboration in a series of sisters. Journal of Child Psychology and Psychiatry 1997; 38:365-374.

48. Van Voorhees E, Scarpa A. The effects of child maltreatment on the hypothalamic-pituitary-adrenal axis. Trauma Violence Abuse 2004; 5:333-352.

49. Shea A, Walsh C, Macmillan H, Steiner M. Child maltreatment and HPA axis dysregulation: relationship to major depressive disorder and post traumatic stress disorder in females. Psychoneuroendocrinology 2005; 30: 162-178.

50. Foley DL, Eaves LJ, Wormley B et al. Childhood adversity, monoamine oxidase a genotype, and risk for conduct disorder. Archives of General Psychiatry 2004; 61:738744.

51. Battle CL, Shea MT, Johnson DM et al. Childhood maltreatment associated with adult personality disorders: findings from the Collaborative Longitudinal Personality Disorders Study. Journal of Personal Disorders 2004; 18:193-211.

52. Luntz BK, Widom CS. Antisocial personality disorder in abused and neglected children grown up. American Journal of Psychiatry 1994; 151:670-674.

53. Horwitz AV, Widom CS, McLaughlin J, White HR. The impact of childhood abuse and neglect on adult mental health: a prospective study. Journal of Health and Social Behavior 2001; 42:184-201.

54. Klonsky ED, Oltmanns TF, Turkheimer E, Fiedler ER. Recollections of conflict with parents and family support in the personality disorders. Journal of Personality Disorders 2000; $14: 327-338$. 
55. Loeber R, Farrington DP, Stouthamer-Loeber M, Moffitt TE, Caspi A, Lynam D. Male mental health problems, psychopathy, and personality traits: key findings from the first 14 years of the Pittsburgh Youth Study. Clinical Child and Family Psychology Review 2001; 4:273-297.
56. Oxford M, Cavell TA, Hughes JN. Callous/unemotional traits moderate the relation between ineffective parenting and child externalizing problems: a partial replication and extension. Journal of Clinical Child and Adolescent Psychology 2003; 32:577-585. 